\title{
Angiogenic Polypoid Proliferation Adjacent to lleal Carcinoid Tumors: A Nonspecific Finding Related to Mucosal Prolapse
}

\author{
Neil A. Abrahams, M.D., Zissis Vesoulis, M.D., Robert E. Petras, M.D. \\ Department of Anatomic Pathology, The Cleveland Clinic Foundation (NAA, REP), Cleveland, Ohio; and \\ Department of Anatomic Pathology, Summa Health System (ZV), Akron, Ohio
}

Case reports have highlighted angiogenic polypoid proliferation in the mucosa adjacent to ileal carcinoid tumors, describing them as granulation tissue polyposis and florid angiogenesis. Some authors have proposed that the ileal carcinoid tumors themselves produce growth factors that cause the change. The purpose of this study was to determine the frequency of angiogenic polypoid proliferation in a large cohort of resected ileal carcinoid tumors compared with control groups.

Search of the Cleveland Clinic and Summa Health System pathology files (1985 to 1999) yielded 65 resected ileal carcinoid tumors. Mucosal abnormalities adjacent to the ileal carcinoid tumors were graded 0 to $4+$. Twenty ileal resection margins from colonic carcinoma cases served as normal controls. Ileal mucosa adjacent to 22 noncarcinoid neoplasms were also examined.

The mucosa adjacent to 54/65 ileal carcinoid tumors (83\%) showed mucosal abnormalities (vs. 3/20 normal controls), including mucosal edema, capillary ectasia, muscularis mucosae hypertrophy, fibrosis/smooth muscle proliferation within the lamina propria, club-shaped villi, and intramucosal capillary proliferation. Forty ileal carcinoid tumor cases $(61 \%)$ showed some degree of angiogenic polypoid proliferation characterized by club-shaped villi and prominent intramucosal capillaries, with $17(26 \%)$ graded as $3+$ or $4+$. Angiogenic polypoid proliferation was associated with hypertrophy of the muscularis mucosae, lamina proprial fibrosis/ smooth muscle proliferation, and capillary ectasia similar to that described with gastrointestinal mu-

Copyright $(\odot 2001$ by The United States and Canadian Academy of Pathology, Inc.

VOL. 14, NO. 9, P. 821, 2001 Printed in the U.S.A.

Date of acceptance: May 1, 2001.

Presented in part at the 89th Annual Meeting of the United States and Canadian Academy of Pathology, March 25-31, 2000, New Orleans, Louisiana.

Address reprint requests to: Robert E. Petras, M.D., The Cleveland Clinic Foundation, Department of Anatomic Pathology, L-25, 9500 Euclid Avenue, Cleveland, OH 44195; e-mail: abrahan@ccf.org;fax: 216-445-2142.

cosal trauma/prolapse. This trauma/prolapse change was identified in 45 cases $(69 \%)$ and was graded $3+$ or $4+$ in 23 (35\%). Seventeen $(77 \%)$ of the noncarcinoid neoplasms showed trauma/prolapse changes, with $7(32 \%)$ graded as $3+$ or $4+$. Angiogenic polypoid proliferation also correlated with trauma/prolapse change in the noncarcinoid neoplasm controls. Neither APP $(P=.24)$ nor the prolapse changes $(P=.33)$ were found to be statistically different between the two tumor groups.

Angiogenic polypoid proliferation of the adjacent ileal mucosa is common in patients with ileal carcinoid tumors and with noncarcinoid neoplasms. Angiogenic polypoid proliferation almost invariably coexists with fibromuscular change and capillary ectasia within the lamina propria, suggesting that mucosal trauma/prolapse plays a role in the histogenesis. The association of angiogenic polypoid proliferation with a variety of different neoplasms makes it unlikely that the tumors themselves secrete growth factors.

KEY WORDS: Angiogenesis, Angiogenic polypoid proliferation, Carcinoid, Granulation tissue polyposis, Mucosal prolapse, Mucosal trauma.

Mod Pathol 2001;14(9):821-827

We previously reported a florid case of angiomatous polyposis (1) associated with an ileal carcinoid tumor adding to only three other previously reported cases $(2,3)$. Angiomatous polyposis is a unique or underrecognized mucosal abnormality that has been reported under various descriptors including granulation tissue polyposis, florid angiogenesis, and angiogenic polypoid proliferation (APP). Grossly, APP presents as an exuberant mucosal polyposis that can simulate cobblestoning. Microscopically, the polyps show varying degrees of club-shaped villi and intramucosal capillary proliferation, ectasia and smooth muscle overgrowth.

In the reported cases to date, the capillary proliferation has been so marked that various authors 
have proposed that the ileal carcinoid tumors themselves were producing angiogenic factors.

The purpose of our study was to determine the frequency of APP in a large cohort of resected ileal carcinoid tumors, compared with that in control groups of resected noncarcinoid small bowel tumors and normal controls.

\section{MATERIALS AND METHODS}

A search of the Cleveland Clinic and Summa Health System pathology files (1985 to 1999) yielded 65 resected ileal carcinoid tumors. Formalin and Hollande's-fixed, paraffin-embedded tissues were routinely processed for light microscopy, sectioned at $5 \mu \mathrm{m}$, and stained by hematoxylin and eosin. In the majority of the cases, the light-microscopic diagnosis of carcinoid tumor was verified with immunostaining for neuron-specific enolase, chromogranin and synaptophysin using the streptavidinbiotin-peroxidase method.

All histologic slides on each case were reviewed (range of slides, 5 to 17; mean number of slides, 6). Pertinent clinical data were retrieved from the medical records.

The mucosa adjacent to the ileal carcinoid tumors was evaluated for the presence of abnormalities including mucosal edema, capillary ectasia (defined as a mucosal capillary lumen with a diameter greater than half of a crypt diameter), muscularis mucosae hypertrophy, smooth muscle proliferation within the lamina propria and angiogenic polypoid proliferation (club-shaped villi with intramucosal capillary proliferation). Intramucosal capillary proliferation was defined as cellular, "glomeruloid" tuft-like structures composed of capillaries. The histologic changes were documented by two independent observers (NAA and REP).

The mucosal abnormalities were graded semiquantitatively from 0 to $4+$, based on the following guidelines: 0 absent; $1+$ mucosal changes observed focally and only at high magnification (400x); $2+$ mucosal changes observed focally and noticeable at medium magnification (200X); $3+$ mucosal changes noticeable immediately at low magnification (40x) with individual foci occupying $<5 \mathrm{~mm}$ in diameter; and $4+$ mucosal changes noticeable immediately at low magnification found in multiple sections with foci of $>5 \mathrm{~mm}$ in diameter.

A cohort of 22 resected noncarcinoid neoplasms of the small bowel was selected as a control group. The fixation and sectioning of the tumors and adjacent mucosa was similar to that described for the carcinoid tumors. The histological diagnoses were reconfirmed, and the ileal mucosa adjacent to these noncarcinoid neoplasms was examined for the mucosal abnormalities cited above and specifically for the features of angiomatous polyposis and similarly graded.

Similar histological evaluation of 20 ileal resection margins from colonic carcinoma cases served as normal controls.

The results of the histological evaluation were expressed in percentages of the total number of cases. To determine whether the mucosal abnormalities were statistically significant between the ileal carcinoid tumor group and the noncarcinoid neoplasms control group, a Fisher's Exact Test was applied. A statistically significant result was defined as a P value of $<0.05$. A Spearman's rank correlation coefficient was used to assess the strength of the relationship between APP and prolapse changes for each of the three groups.

\section{RESULTS}

The mean age of presentation for the ileal carcinoid tumor group was 70 years (range, 40 to 81 ) with a F:M ratio of $2: 1$. In the noncarcinoid neoplasm group, the mean age of presentation was 64 years (range, 23 to 82 ) with a F:M ratio of 1.2:1. The mean tumor size in the ileal carcinoid tumors group was $2.4 \mathrm{~cm}$, with 11 of the cases presenting as multiple nodules. In the noncarcinoid neoplasm group, the mean tumor size was $2.0 \mathrm{~cm}$. The carcinoids were all typical midgut insular type tumors with finely stippled chromatin of the nuclei and rare mitoses and no necrosis. The noncarcinoid tumor group comprised 12 metastatic carcinomas (of which 4 were metastatic ovarian carcinomas and 1 was a breast carcinoma), 2 gastrointestinal stromal tumors, 2 primary adenocarcinomas of small bowel, 2 lymphomas, 1 mesothelioma, 1 lipoma, and 2 leiomyosarcomas. In four of the cases, from the carcinoid tumor group, various submucosal tumors of the small bowel were grossly identified, and the adjacent and overlying mucosa showed a profusion of sessile polyps. (Figs. 1 and 2.)

Both observers agreed on the grade of mucosal changes in $85 \%$ of the observations. Discrepancies were usually of one grade only and were resolved in consultation using a teaching microscope. The final consensus grades were used for comparison.

\section{Resected Ileal Carcinoid Tumors}

The mucosa adjacent to 54 (83\%) ileal carcinoid tumors showed some degree of histologic abnormality including mucosal edema, capillary ectasia, muscularis mucosae hypertrophy, proliferation of club-shaped villi with prominent intramucosal capillary proliferation. Forty ileal carcinoid tumors (61\%) showed some degree of mucosal angiogenic polypoid proliferation $(\geq 2+)$, with $17(26 \%)$ graded as $3+$ or $4+$ (Figs. 3 and 4). Thirty-two ileal carci- 


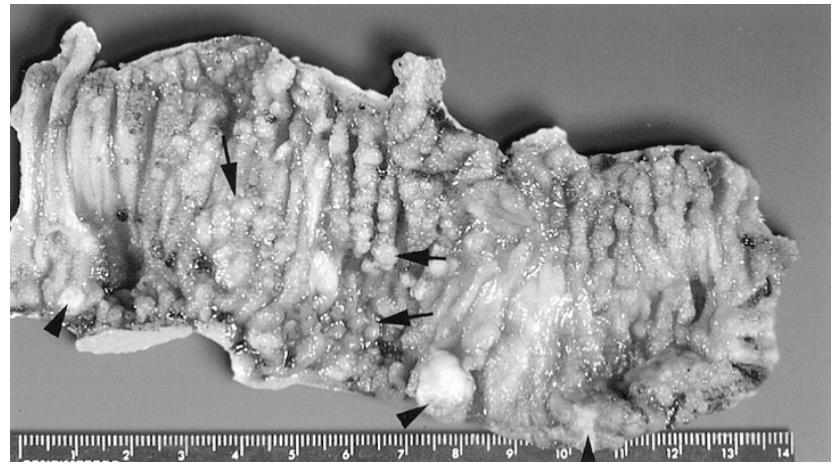

FIGURE 1. Ileal carcinoid tumor (arrowheads) and adjacent polyposis (arrows) of ileal mucosa.

noid neoplasms (49\%) showed intramucosal capillary proliferation, with $12(18 \%)$ graded as $3+/ 4+$. APP was associated with hypertrophy of the muscularis mucosae, lamina proprial fibrosis/smooth muscle proliferation and capillary ectasia similar to that described with gastrointestinal mucosal trauma/prolapse syndromes in $83 \%$ of the cases. The trauma prolapse change was identified in 45 (69\%) of the carcinoid tumor cases and was graded $3+$ or $4+$ in $23(35 \%)$ of the cases. A level of correlation (Spearman's $r=.423$ ) was found between APP and the mucosal trauma/prolapse changes that was highly significant $(P<.001)$.

\section{Resected Noncarcinoid Neoplasms Control Group}

Sixteen $(72 \%)$ of the noncarcinoid neoplasms showed some degree of angiomatous polyposis

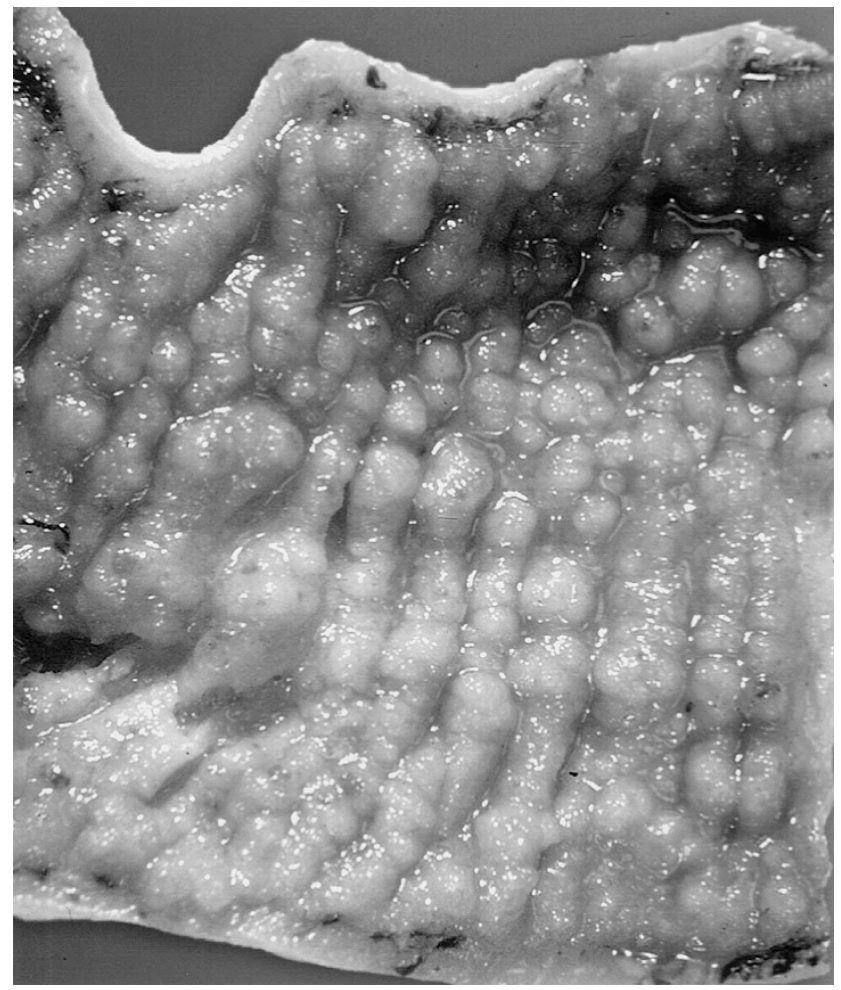

FIGURE 2. Ileal carcinoid tumor with sessile polyps of overlying mucosa with a "cobblestone" appearance.

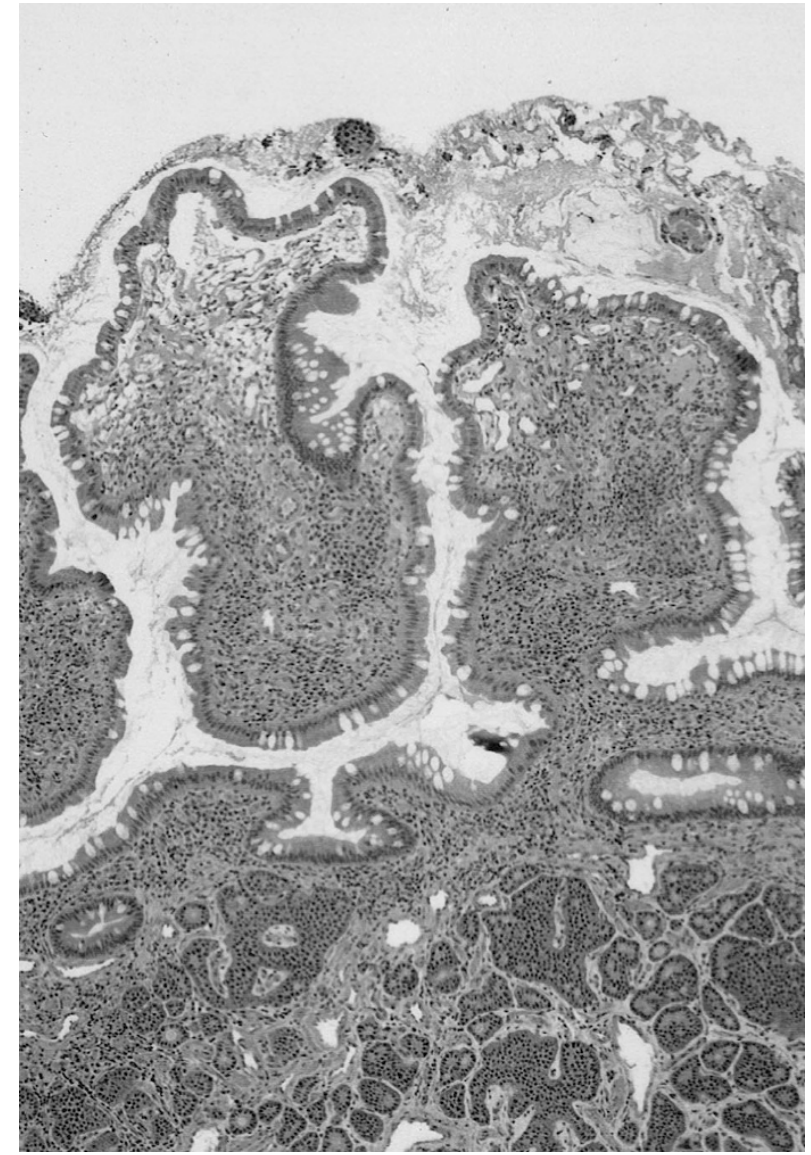

FIGURE 3. Angiogenic polypoid proliferation (Grade 4+) of mucosa adjacent to an ileal carcinoid tumor.

with 5 (23\%) graded as $3+$ or $4+$ (Figs. 5 and 6 ). Twelve noncarcinoid neoplasms $(55 \%)$ showed intramucosal capillary proliferation $(\geq 2+)$, with 3 (14\%) graded as $3+/ 4+$. Angiomatous polyposis was associated with hypertrophy of the muscularis mucosae, lamina proprial fibrosis/smooth muscle proliferation and capillary ectasia similar to that described with gastrointestinal mucosal trauma/ prolapse syndromes in $100 \%$ of the cases. The trauma prolapse change was identified in $17(77 \%)$ of the cases and was graded $3+$ or $4+$ in $7(32 \%)$ of the cases. A greater degree of correlation was found between APP and the mucosal trauma/prolapse changes in the noncarcinoid group (Spearman's rank correlation $r=.645)$ than in the carcinoid group. This correlation was highly significant $(P=$ $.001)$.

\section{Normal Ileal Mucosa Controls}

Three normal resected ileal mucosa controls (15\%) showed some degree of mucosal angiogenic polypoid proliferation. Similarly, three (15\%) of the cases showed intramucosal capillary proliferation with none graded as $3+/ 4+$. The trauma prolapse change was identified in $2(10 \%)$ of the cases. Minor trauma prolapse changes $(1+)$ were identified in 8 


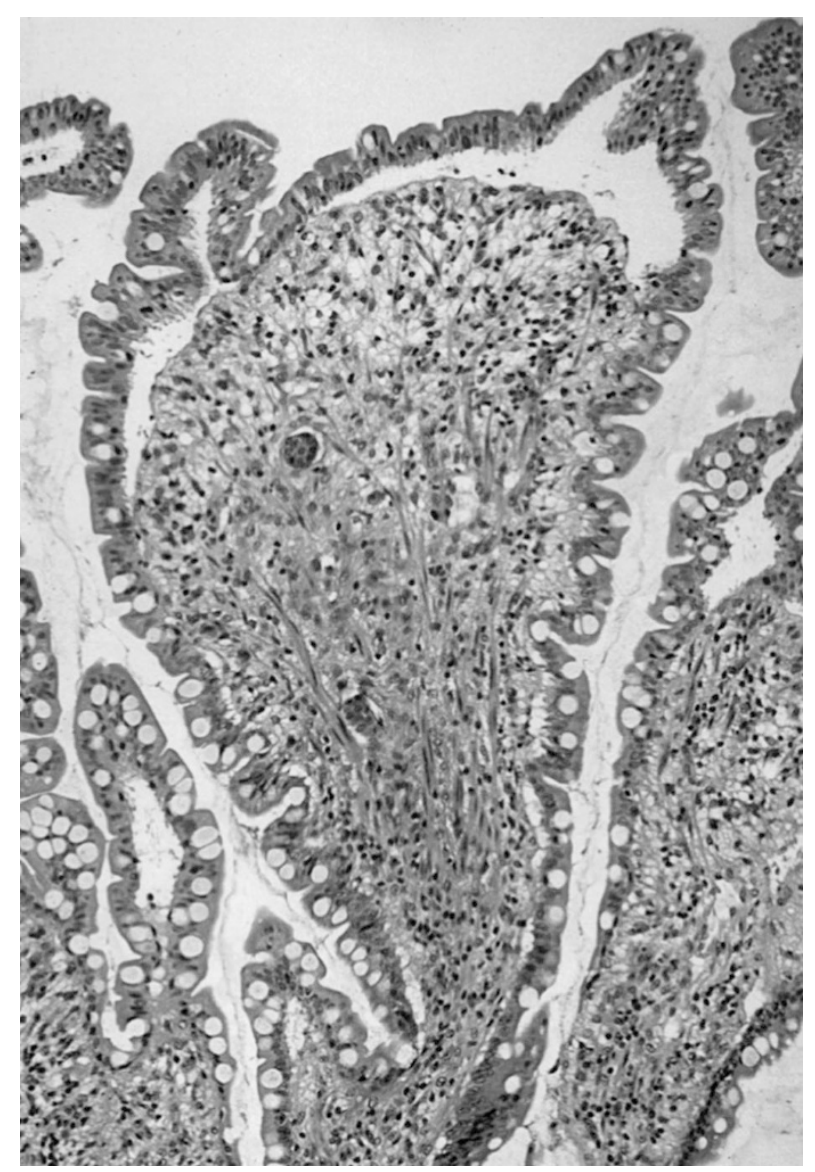

FIGURE 4. Large club-shaped or squared-off villi of mucosa from an ileal carcinoid tumor, with fibromuscular proliferation and lamina proprial capillary ectasia. Note carcinoid tumor present in lymphatic spaces.

(40\%) of the cases. The association between the APP and the mucosal trauma/prolapse changes was the strongest for the control group (Spearman's $r=.745$ ), and this result was highly significant $(P<.001)$.

Comparison of mucosal abnormalities in the ileal carcinoid tumors cohort to the noncarcinoid neoplasms and control group are summarized in Table 1.

The presence of APP was not significantly different between the ileal carcinoid tumor group and the non-carcinoid group $(P=.24)$. Similar nonsignificant results were found for prolapse changes between the two groups $(P=.33)$.

The frequency and statistical significance of angiogenic polypoid proliferation and trauma/prolapse changes in resected ileal carcinoid tumors is compared with that of non-carcinoid neoplasms and control group (Table 2).

\section{DISCUSSION}

In 1993, Allibone and colleagues (2) reported two cases of ileal carcinoid-related angiomatous polyposis, which they described as granulation tissue polyposis. Several years later, Cai et al. (3) described

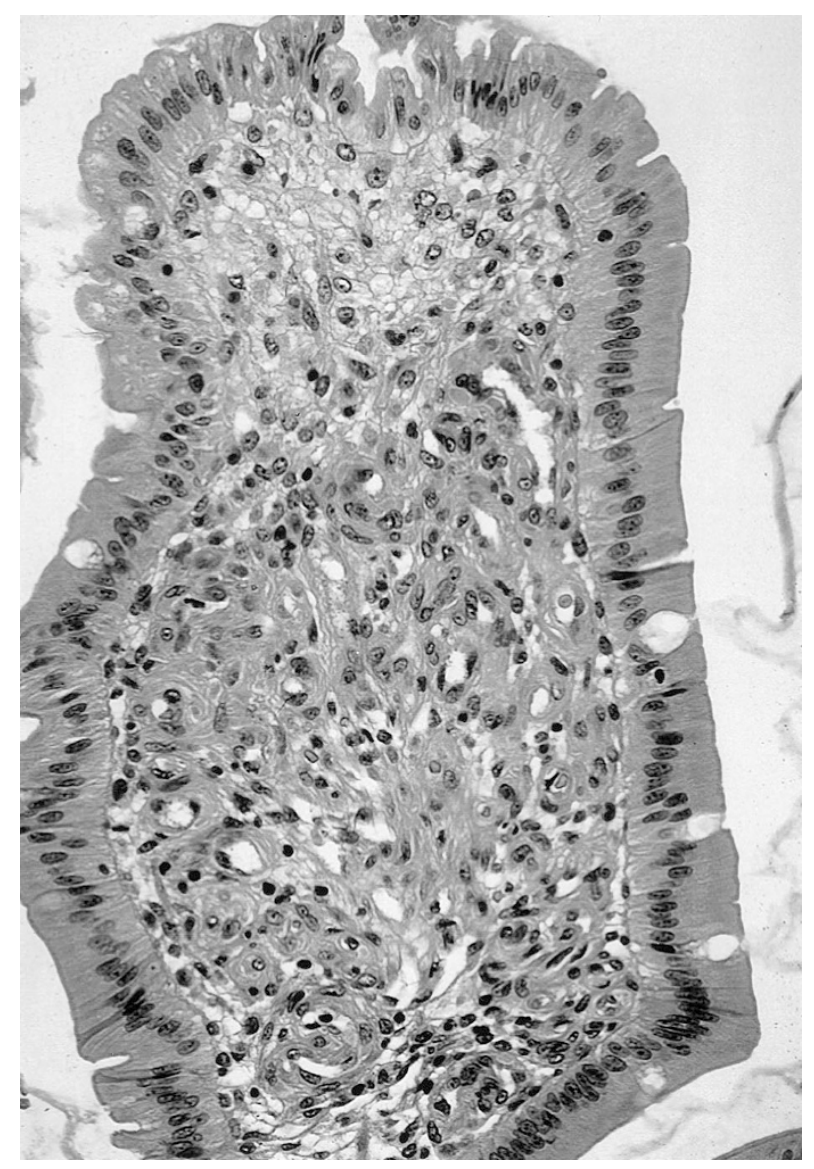

FIGURE 5. Angiogenic polypoid proliferation (Grade 4+) of mucosa adjacent to a noncarcinoid neoplasm of small bowel (mesothelioma).

a case of florid angiogenesis in the mucosa surrounding a resected ileal carcinoid tumor. We subsequently described an additional case (1). These angiogenic polypoid proliferations (APP) were so dramatic that they prompted some authors $(2,3)$ to suggest that the carcinoid tumors themselves were secreting angiogenic growth factors, particularly TGF $\alpha$ and TGF $\beta$, that may be responsible for the APP. The frequency of APP in resected carcinoid tumors of the small bowel is not known, and furthermore, the specificity of the described changes to carcinoid tumors has not been studied. Therefore, we sought to objectively evaluate any morphological alteration associated with ileal carcinoid and other small-bowel neoplasms.

Surprisingly, a variety of small-bowel neoplasms including primary and metastatic adenocarcinoma, gastrointestinal stromal tumor, and lymphoma demonstrated similar morphological changes in the adjacent mucosa. We found that $61 \%$ of the ileal carcinoid tumors showed some degree of APP and found an even greater number (72\%) of the noncarcinoid neoplasms that showed APP. The degree of APP was also similar, with $26 \%$ of the carcinoid neoplasms graded as $3+$ or $4+$ for APP, versus $23 \%$ of the non-carcinoid neoplasms. Furthermore, the 


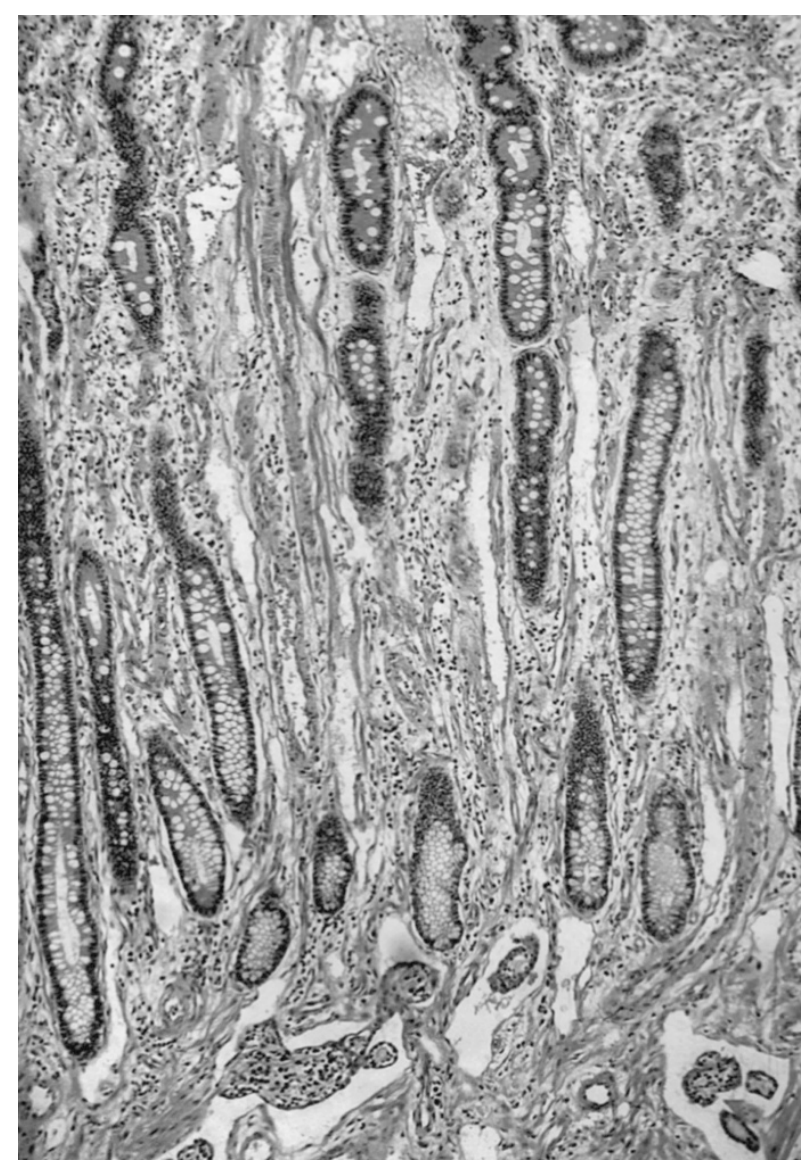

FIGURE 6. Fibromuscular proliferation and lamina proprial capillary ectasia from a case of noncarcinoid neoplasm of small bowel (metastatic ovarian carcinoma).

presence of APP $(P=.24)$ or prolapse changes $(P=$ .33) was not significantly different between the ileal carcinoid tumor group and the non-carcinoid group. This indicates that the mucosal changes cannot be taken as specific to ileal carcinoids. The changes of APP are similar to those described to mucosal trauma/prolapse as in other parts of the gastrointestinal tract $(4,5)$. These findings suggest that it is unlikely that a variety of tumors, of varying histogenesis, themselves all secrete the proposed growth factors. Similar histologic findings suggest consideration of a mechanical prolapse. Our previous experience (1) with various cytokines that have been postulated as the cause of APP, namely transforming growth factor alpha (TGF- $\alpha$ ) and transforming growth factor beta 1 and 3 (TGF- $\beta$ 1,3), showed little expression of these cytokines in the ileal carcinoid tumors and their surrounding mucosa. These cytokines have been implicated in the proliferative changes in fibroblasts and endothelial cells in both local and distant end organs (6-8). These cytokines have not been associated, to our knowledge, with prolapse changes in noncarcinoid neoplasms.

The immunohistochemical expression of transforming growth factors in gastrointestinal carci- noids has been studied, and in one article, the findings indicated that $\mathrm{TGF} \alpha$ was expressed by a high proportion of gastrointestinal carcinoids (72\%); however, the absence of an intact receptor molecule on the tumor cells renders it functionally ineffective as a growth factor (7).

We suggest, based on the results of the present study, that APP is a nonspecific change and that this is further supported by the association of APP with fibromuscular changes seen in mucosal prolapse/trauma. APP was associated with mucosal prolapse/trauma in $83 \%$ of the cases of carcinoid neoplasms as opposed to in $100 \%$ of the noncarcinoid neoplasms group. The correlation between APP and mucosal trauma/prolapse changes in the noncarcinoid tumor group (Spearman's $r=.645$; $P$ $=.001$ ) further supports these observations. The association of fibromuscular changes characteristic of mucosal prolapse/trauma suggests that this could be a common pathway for APP. The formation of a polyposis with mucosal prolapse has been described in pelvic ileal reservoirs (9), solitary rectal ulcer syndrome $(10,11)$, inflammatory cloacogenic polyps (5), prolapsing stomas and rectal prolapse (12), polyps of Cowden disease (13), and gastric antral vascular ectasia (14). These findings were present in both the carcinoid cohort (69\%) and the noncarcinoid cohort (77\%).

Florid vascular proliferations have been associated with neural and neuroendocine neoplasms of varied locations, neuroblastoma, teratoma, primitive neuroectodermal tumor, and thyroid medullary carcinoma (15). However the vascular proliferations of these cases were found within the fibrous stroma of the neoplasms between lobules of tumor. The APP described in our series was located in the mucosa adjacent to the carcinoid tumors. Furthermore, the vascular proliferations reported by Gaudin and Rosai (15) were described as a compact tuft of proliferating endothelial cells resembling a renal glomerulus, which differs from APP. The importance of recognizing APP resides in the possible misdiagnosis of Crohn's disease if based on radiological and clinical parameters alone (16). Numerous reports highlight cases of terminal ileum carcinoid tumors with a presentation simulating Crohn's disease (17). Pathologically, the polypoid mucosa, fibrosing strictures, and mucosal ulceration may suggest Crohn's, but the overt presence of an associated submucosal neoplasm as well as the histologic features eventually lead to the correct diagnosis.

The finding of APP associated with mucosal trau$\mathrm{ma} /$ prolapse in both the carcinoid and noncarcinoid cohorts makes it unlikely that this unique mucosal alteration is solely due to the secretion of growth factors by carcinoid tumors. Clearly, the angiogenesis may be related to the secretion of 


\begin{tabular}{|c|c|c|c|c|c|c|}
\hline \multirow[t]{2}{*}{ Features } & \multicolumn{2}{|c|}{$\begin{array}{c}\text { Ileal } \\
\text { Carcinoid } \\
\text { Tumors }\end{array}$} & \multicolumn{2}{|c|}{$\begin{array}{r}\text { Noncarcinoid } \\
\text { Neoplasms }\end{array}$} & \multicolumn{2}{|c|}{ Normal Ileal Mucosa (Control) } \\
\hline & $n$ & $\%$ & $n$ & $\%$ & $n$ & $\%$ \\
\hline \multicolumn{7}{|l|}{ Capillary ectasia } \\
\hline 0 & 13 & 20 & 3 & 14 & 13 & 65 \\
\hline $1+$ & 14 & 22 & 10 & 45 & 6 & 30 \\
\hline $2+$ & 21 & 32 & 4 & 18 & 1 & 5 \\
\hline $3+/ 4+$ & 17 & 26 & 5 & 23 & 0 & 0 \\
\hline \multicolumn{7}{|c|}{ Fibromuscular hyperplasia } \\
\hline 0 & 7 & 11 & 0 & 0 & 10 & 50 \\
\hline $1+$ & 13 & 20 & 5 & 23 & 8 & 40 \\
\hline $2+$ & 22 & 34 & 10 & 45 & 2 & 10 \\
\hline $3+/ 4+$ & 23 & 35 & 7 & 32 & 0 & 0 \\
\hline \multicolumn{7}{|l|}{ Club shaped villi } \\
\hline 0 & 5 & 8 & 3 & 14 & 14 & 70 \\
\hline $1+$ & 20 & 31 & 3 & 14 & 4 & 20 \\
\hline $2+$ & 23 & 35 & 11 & 50 & 2 & 10 \\
\hline $3+/ 4+$ & 17 & 26 & 5 & 23 & 0 & 0 \\
\hline \multicolumn{7}{|c|}{$\begin{array}{l}\text { Intramucosal capillary } \\
\text { proliferation }\end{array}$} \\
\hline 0 & 6 & 9 & 1 & 5 & 15 & 75 \\
\hline $1+$ & 27 & 42 & 9 & 41 & 2 & 10 \\
\hline $2+$ & 20 & 31 & 9 & 41 & 3 & 15 \\
\hline $3+/ 4+$ & 12 & 18 & 3 & 14 & 0 & 0 \\
\hline Total & 65 & 100 & 22 & 100 & 20 & 100 \\
\hline
\end{tabular}

TABLE 2. Angiogenic Polypoid Proliferation and Mucosal Changes Characteristic of Prolapse in Ileal Carcinoid Tumors, Noncarcinoid Neoplasms, and Control Group

\begin{tabular}{|c|c|c|c|c|c|c|c|}
\hline \multirow[t]{2}{*}{ Features } & \multicolumn{2}{|c|}{$\begin{array}{l}\text { Ileal Carcinoid } \\
\text { Tumors }\end{array}$} & \multicolumn{2}{|c|}{$\begin{array}{l}\text { Noncarcinoid } \\
\text { Neoplasms }\end{array}$} & \multirow[t]{2}{*}{$P$ Value } & \multicolumn{2}{|c|}{$\begin{array}{c}\text { Normal Ileal } \\
\text { Mucosa } \\
\text { (Control) }\end{array}$} \\
\hline & $n$ & $\%$ & $n$ & $\%$ & & $n$ & $\%$ \\
\hline Any APP & 40 & 61 & 16 & 72 & $P=.24$ & 3 & 15 \\
\hline APP $3+/ 4+$ & 17 & 26 & 5 & 23 & $P=.49$ & 0 & 0 \\
\hline Any prolapse changes & 45 & 69 & 17 & 77 & $P=.33$ & 2 & 10 \\
\hline Prolapse Changes $3+/ 4+$ & 23 & 35 & 7 & 32 & $P=.48$ & 0 & 0 \\
\hline $\begin{array}{l}\text { Number of APP } 3+/ 4+\text { with } \\
3+/ 4+\text { prolapse changes }\end{array}$ & $14 / 17$ & 83 & $5 / 5$ & 100 & NA & $0 / 0$ & 0 \\
\hline
\end{tabular}

APP, angiogenic polypoid proliferation; NA, not applicable.

growth factors; however, we believe that these factors are nonspecific and may in fact be more related to trauma and inflammation. These cytokines could be released from the surrounding inflammatory cells, such as macrophages, which are common in these tumors.

The presently described APP was invariably associated with other changes commonly described in mucosal trauma/prolapse, and because these changes seem to occur regardless of tumor type, we postulate that the APP is in fact an exaggerated form of mucosal prolapse. The presence of some minor changes characteristic of mucosal prolapse/ trauma in normal ileum suggests that some physiologic trauma may be present in the area of the ileocecal valve in normal individuals.

\section{REFERENCES}

1. Vesoulis Z, Abrahams N, Becker J, Slezak F. Carcinoidrelated angiomatous polyposis simulating Crohn disease. Arch Pathol Lab Med 2000;124:450-4.

2. Allibone RO, Hoffman J, Gosney JR, Helliwell TR. Granulation tissue polyposis associated with carcinoid tumours of the small intestine. Histopathology 1993;22:475-80.

3. Cai YC, Barnard G, Hiestand L, Woda B, Colby J, Banner B. Florid angiogenesis in mucosa surrounding an ileal carcinoid tumor expressing transforming growth factor-alpha. Am J Surg Pathol 1997;21:1373-7.

4. Kelly JK. Polypoid prolapsing mucosal folds in diverticular disease. Am J Surg Pathol 1991;15:871-8.

5. Saul SH. Inflammatory cloacogenic polyp: relationship to solitary rectal ulcer syndrome/mucosal prolapse and other bowel disorders. Hum Pathol 1987;18:1120-5.

6. Beauchamp RD, Coffey RJ, Lyons RM, Perkett EA, Townsend CM Jr, Moses HL. Human carcinoid cell production of para- 
crine growth factors that can stimulate fibroblast and endothelial growth. Cancer Res 1991;51:5253-60.

7. Nilsson O, Wangberg B, McRae A, Dahlstrom A, Ahlman H. Growth factors and carcinoid tumours. Acta Oncol 1993;32: $115-24$.

8. Krishnamurthy S, Dayal Y. Immunohistochemical expression of transforming growth factor alpha and epidermal growth factor receptor in gastrointestinal carcinoids. Am J Surg Pathol 1997;21:327-33.

9. Blazeby JM, Durdey P, Warren BF. Polypoid mucosal prolapse in a pelvic ileal reservoir. Gut 1994;35:1668-9.

10. Lobert PF, Appleman HD. Inflammatory cloacogenic polyp. A unique inflammatory lesion of the anal transition zone. Am J Surg Pathol 1981;5:761-6.

11. du Boulay CEH, Fairbrother J, Isaacson PG. Mucosal prolapse syndrome-a unifying concept for solitary ulcer syndrome and related disorders. J Clin Pathol 1983;36: 264-8.
12. Schweiger M, Alexander-Williams J. Solitary-ulcer syndrome of the rectum. Its associations with occult rectal prolapse. Lancet 1977;1:170-1.

13. Carlson GJ, Nivatongs S, Snover DC. Colorectal polyps in Cowden's disease (multiple hamartoma syndrome). Am J Surg Pathol 1984;8:763-70.

14. Suit PF, Petras RE, Bauer TW, Petrini JL. Gastric antral vascular ectasia. A histologic and morphometric study of "the watermelon stomach” Am J Surg Pathol 1987;11:750-7.

15. Gaudin PB, Rosai J. Florid vascular proliferation associated with neural and neuroendocrine neoplasms. A diagnostic clue and potential pitfall. Am J Surg Pathol 1995;19:642-52.

16. Hsu EY, Feldman JM, Lichtenstein GR. Ileal carcinoid tumors simulating Crohn's disease: incidence among 176 consecutive cases of ileal carcinoid. Am J Gastroenterol 1996;92:2062-5.

17. Mir-Madjlessi SH, Winkelman EI, Davis GA. Carcinoid tumors of the terminal ileum simulating Crohn's disease. Cleve Clin J Med 1988;55:257-62. 